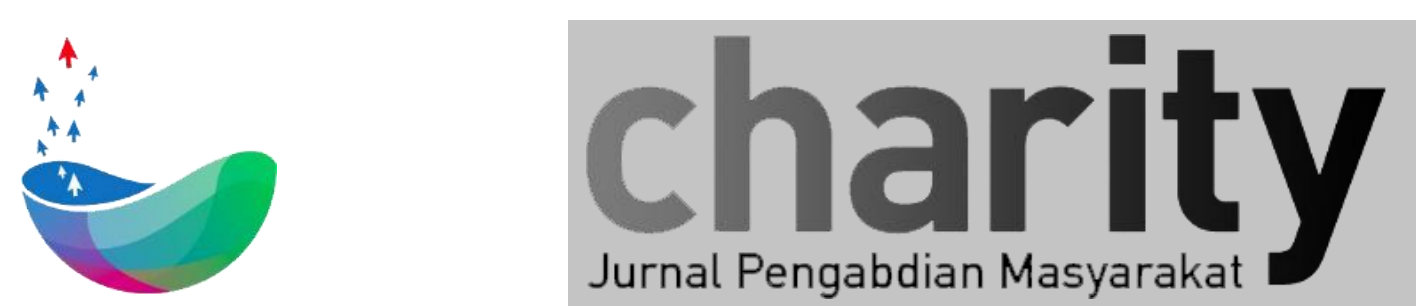

\title{
MEKANISASI PROSES PRODUKSI OPAK KETAN GUNA MENINGKATKAN KUALITAS DAN PRODUKTIVITAS DI DESA KAREDOK KECAMATAN CATIGEDE KABUPATEN SUMEDANG
}

\author{
Rosad Ma'ali El Hadi ${ }^{1 *}$, Kemas Muslim Lhaksmana ${ }^{2}$, Agus Ahmad Suhendra ${ }^{3}$, Haryono Lalu ${ }^{4}$ \\ 1,3,4 Teknik Industri, Fakultas Rekayasa Industri, Universitas Telkom, ${ }^{2}$ Teknik Informatika, Fakultas Informatka, Universitas Telkom \\ * rosadm@telkomuniversity.ac.id, kemasmuslim@telkomuniversity.ac.id, agus@ telkomuniversity.ac.id, heryonolalu@telkomuniversity.ac.id
}

\section{INFO ARTIKEL}

Diterima 18 Desember 2021

Direvisi 25 Januari 2022

Disetujui 26 Januari 2022

Tersedia Online 26 Januari 2022

Keyword Mesin Produksi, opak ketan

Korespondensi:

\begin{abstract}
ABSTRAK
Objek pengabdian masyarakat Telkom University bekerjasama dengan CSR PT. PLN (Persero) UPP - JBT 2, adalah usaha rumah tangga yang membuat opak ketan dengan proses secara manual/tradisional. Proses penumbukan masih menggunakan tenaga kerja mulai menumbuk pada jam 01.00 selesai jam 06.00 dengan jumlah beras ketan sebanyak $40 \mathrm{~kg}$ yang dimasak menjadi nasi ketan.. Proses pencetakan menggunakan alat cetak 1 operator 1 alat cetak menghasilkan 1 kepang opak ketan basah. Proses pengeringan dengan memanfaatkan sinar matahari, memerlukan lahan yang cukup luas, kurang higienis, bila hujan tiba repon menyelamatkan jemuran serta bila cuaca mendung, tidak akan bias mengeringkan opak ketan basah, begitupun malam hari tidak bias berproduksi. Pematangan makanan dengan cara pematangan, dimana makanan diletakkan di atas kawat ram yang diletakkan di atas tungku bara api, 1 orang 1 alat pematangan dan maksimum 40 keping opak ketan kering per pematangan dengan waktu ratarata 9 menit. Kualitas opak ketan yang dihasilkan sangat bergantung dari ketrampilan karyawan dan ketepatan saat menumbuk nasi ketan, mencetak, mengeringkan dan membolak-balik opak agar memperoleh hasil yang baik, dalam kenyataannya kualitas opak hasil pematangan bervariasi. Selain itu hasil produksi yang terbatas, menyebabkan permintaan yang tinggi dari pelanggan sering tidak dapat dipenuhi oleh pengrajin opak tersebut. Guna mengatasi masalah tersebut, maka tim pengabdian masyarakat Telkom University, membuat dan mendesiminasikan mesin penumbuk nasi ketan dengan metode transmisi, alat pencetak opak ketan dengan system noken as, oven multi produk dengan sistem udara panas dan mesin pematangan opak ketan dengan metode roller.

Mesin penumbuk dengan metode transmisi dapat menumbuk nasi ketan sebanyak $4 \mathrm{~kg}$ dalam waktu 6 menit. Alat cetak dengan sistem noken as dapat mencetak 8 keping opak ketan basah dalam satu kali pencetakan. Oven multi produk dengan sistem udara panas dapat mengeringkan opak ketan sebanyak 400 keping opak dalam waktu 25 menit. Mesin pematangan opak ketan dengan metode roller dapat mematangkan opak ketan sebanyak 800 keping opak ketan dalam kurun waktu 15 menit. Pemanfaatan mesin produksi opak ketan, dapat meningkatkan kualitas, produktivitas, ekonomis dan kontinyuitas produksi, sehingga permintaan akan opak ketan dapat terpenuhi.
\end{abstract}




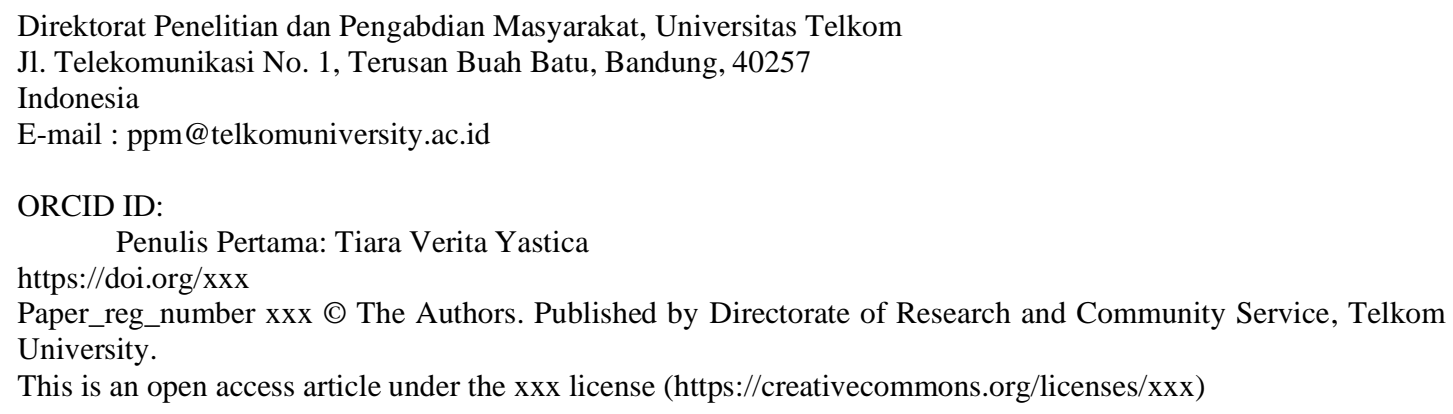

\section{Pendahuluan}

Desa Karedok terkenal akan produksi opaknya dan sampai saat ini para produsennya telah memenuhi pesanan dari berbagai kota di Jawa Barat, seperti Majalengka, Cirebon, Bandung Raya, Garut dan Cianjur.

Pengrajin opak ketan merupakan pelaku salah satu industri kreatif di bidang kuliner, opak ketan merupakan makanan ringan khas Jawa Barat dan memiliki potensi untuk berkembang sampai ke luar Jawa Barat. Industri Kreatif dalam bidang kuliner ini pada umumya sudah memiliki pasar yang luas dan dapat bersaing dengan pasar ritel modern, karena memiliki nilai ekonomis lebih namun tetap mendapatkan laba. Berdasarkan survei awal ke desa Karedok, proses produksi opak ketan dapat dilihat pada Gambar 1.

Gambar 1. Alur Proses Pembuatan Opak Ketan

Gambar 1 memperlihatkan proses pembuatan opak ketan dan permasalahan yang masih dihadapi oleh kelompok pengrajin opak ketan yaitu masih menggunakan teknologi tradisional dalam melakukan penumbukan nasi ketan sebagai bahan baku opak ketan lihat Gambar 2, 3, 4 dan 5, sehingga produktivitasnya sangat rendah, sedangkan permintaan (pasar) opak ketan sangat tinggi, sehingga sebagian permintaan tidak dapat terpenuhi, maka perlu dibuat dan diimplementasikan (diterapkan) sistem dan teknologi tepat guna agar dapat mengatasi masalah yang dialami pengrajin opak ketan.

Proses yang paling krusial dalam pembuatan opak ketan tersebut dan menjadi prioritas utama adalah proses penumbukan nasi ketan, karena jika nasi ketan yang sudah ditumbuk masih kasar atau kurang lembut, maka akan mempengaruhi kualitas opak ketan berdampak pada buruknya kualitas opak ketan jadi, prioritas 2, 3 dan ke 4 secara berurutan adalah mesin pematangan opak ketan, meain pencetak opak ketan dan oven pengeringan opak ketan, maka diperlukan inovasi pembuatan mesin produksi opak ketan guna meningkatkan kualitas, produktivitas dan ekonomis.

Proses pembuatan dan ujicoba penggunaan mesin penumbuk, alat cetak, oven dan pematang opak ketan dengan metode roller, diharapkan masalah yang dihadapi oleh pengrajin opak ketan dapat diatasi, produktivitas meningkat, lebih ekonomis dan proses produksi tidak dibatasi oleh ketrampilan karyawan, sehingga permintaan pelanggan dapat terpenuhi.

\section{Metodologi}

Program pengembangan teknologi wirausaha pembuatan opak ketan ini melalui beberapa tahapan proses. Metodologi pelaksanaan pengabdian 
masyarakat dalam rangka sosialisasi dan implementasi mekanisasi proses produksi opak ketan dengan memanfaatkan teknologi tepat guna, dapat dilihat pada Gambar 2.

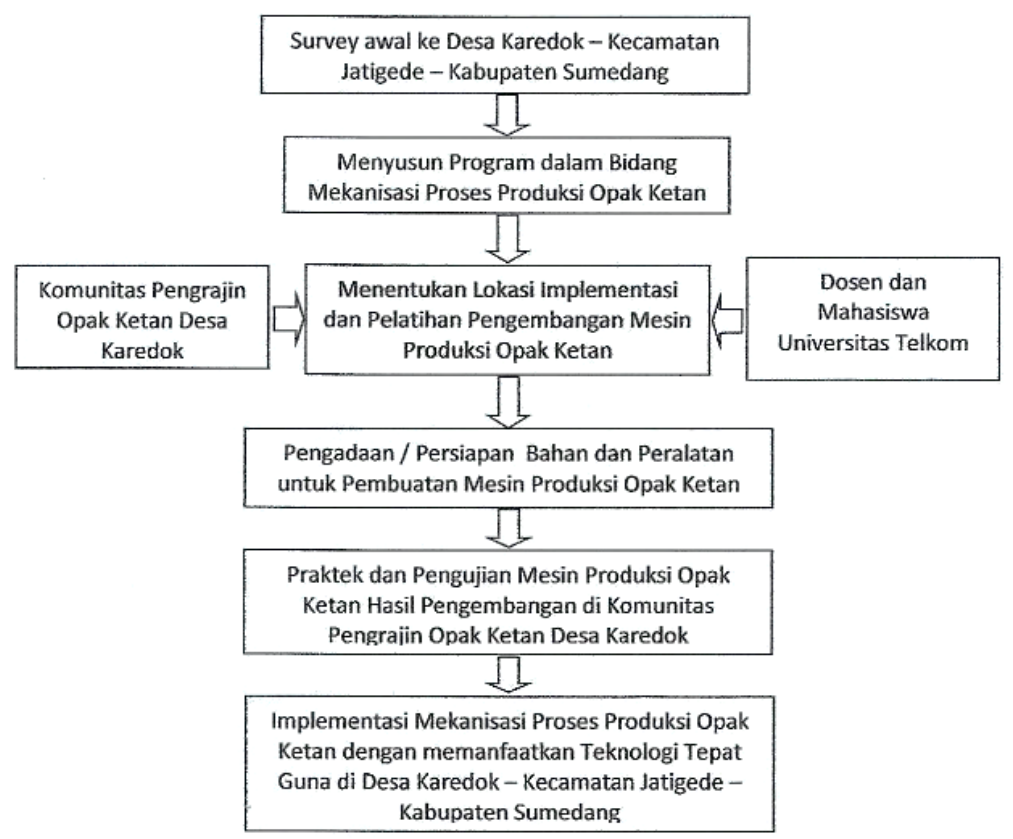

Gambar 2. Metodologi Mekanisasi Proses Produksi Opak Ketan

Gambar 2 memperlihatkan metodologi pelaksanaan Pengabdian Masyarakat skema Kolaborasi Eksternal yaitu proses peningkatan kualitas dan produktivitas pengrajin opek ketan Desa Karedok Kecamatan Jatigede Sumedang, dengan memanfaatkan teknologi tepat guna, sehingga permintaan pasar akan opak ketan dapat terpenuhi.

\section{Hasil dan Pembahasan}

Proses produksi opak ketan di Desa Karedok Kecamatan Buahdua Kabupaten Sumedang dilakukan secara manual (konvensional), mulai dari proses penumbukan nasi ketan, pencetakan opak ketan, pengeringan dan pematangan opak ketan. Hal tersebut menyebabkan produktivitas rendah, permintaan pasar tidak dapat terpenuhi apalagi bila musim penghujan, terjadi penurunan jumlah produksi sampai $40 \%$.

Mekanisasi proses produksi opak ketan dapat meningkatkan produktivitas dan kualitas serta tidak dipengaruhi oleh musin, saat musim penghujan pengrajin opak ketan masih dapat memproduksi opak ketan, sehingga pasar dapat terpenuhi secara berkesinambungan. Perbandingan proses produksi opak ketan sebelum dan sesudah pelaksanaan Pengabdian Masyarakat, dapat dilihat pada Tabel 1 . 
Tabel 1. Perbandingan Proses Produksi Opak Ketan Sebelum dan Sesudah Pengmas

\begin{tabular}{|c|c|c|}
\hline \multicolumn{3}{|c|}{ A. Proses Produksi Sebelum Pengmas } \\
\hline Kegiatan & Foto & Kapasitas/Waktu \\
\hline $\begin{array}{l}\text { Menumbuk nasi } \\
\text { ketan }\end{array}$ & & $\begin{array}{l}40 \mathrm{~kg} \text { beras ketan dimasak menjadi nasi } \\
\text { ketan, ditum-buk selama } 5 \text { jam }\end{array}$ \\
\hline $\begin{array}{l}\text { Mencetak opak } \\
\text { ketan }\end{array}$ & & $\begin{array}{l}\text { Satu kali mence-tak menghasil-kan } 1 \text { keping } \\
\text { opak ketan, dilakukan oleh } 5 \text { orang selama } \\
3 \text { jam }\end{array}$ \\
\hline $\begin{array}{l}\text { Menjemur dengan } \\
\text { memanfaatkan sinar } \\
\text { matahari }\end{array}$ & & Selama 5 jam \\
\hline $\begin{array}{l}\text { Mematangkan opak } \\
\text { ketan }\end{array}$ & & $\begin{array}{l}4 \text { tungku, oleh } 4 \text { orang pekerja dengan } \\
\text { waktu } 3 \text { jam }\end{array}$ \\
\hline \multicolumn{3}{|c|}{ B. Proses Produksi Sesudah Pengmas } \\
\hline Kegiatan & Foto & Kapasitas/Waktu \\
\hline $\begin{array}{l}\text { Menumbuk nasi } \\
\text { ketan }\end{array}$ & & $\begin{array}{l}40 \mathrm{~kg} \text { beras ketan dimasak menjadi nasi } \\
\text { ketan, ditumbuk selama } 1,5 \text { jam }\end{array}$ \\
\hline $\begin{array}{l}\text { Mencetak opak } \\
\text { ketan }\end{array}$ & & $\begin{array}{l}\text { Satu kali mence-tak menghasil-kan } 6 \text { keping } \\
\text { opak ketan, dilakukan oleh } 1 \text { orang selama } \\
1 \text { jam }\end{array}$ \\
\hline $\begin{array}{l}\text { Menjemur dengan } \\
\text { memanfaatkan sinar } \\
\text { matahari }\end{array}$ & & Selama 1 jam \\
\hline $\begin{array}{l}\text { Mematangkan opak } \\
\text { ketan }\end{array}$ & & $\begin{array}{l}1 \text { Mesin, } 1 \text { orang pekerja dengan waktu } 1 \\
\text { jam }\end{array}$ \\
\hline \multicolumn{3}{|c|}{ C. Penghematan Waktu Memanfaatkan Mesin } \\
\hline Kegiatan & \multicolumn{2}{|c|}{ Penghematan } \\
\hline $\begin{array}{l}\text { Menumbuk nasi } \\
\text { ketan }\end{array}$ & \multicolumn{2}{|c|}{$\begin{array}{l}40 \mathrm{~kg} \text { beras ketan dimasak menjadi nasi ketan, penghematan } \\
\text { waktu menumbuk selama 3,5 jam. }\end{array}$} \\
\hline $\begin{array}{l}\text { Mencetak opak } \\
\text { ketan }\end{array}$ & \multicolumn{2}{|c|}{$\begin{array}{l}\text { Satu kali mencetak menghasilkan } 6 \text { keping opak ketan, dilakukan } \\
\text { oleh } 1 \text { orang, penghematan wakyu mencetak selama } 2 \text { jam. }\end{array}$} \\
\hline $\begin{array}{l}\text { Menjemur dengan } \\
\text { memanfaatkan sinar } \\
\text { matahari }\end{array}$ & \multicolumn{2}{|c|}{ Penghematan waktu pengeringan opak ketan selama 4 jam } \\
\hline $\begin{array}{l}\text { Mematangkan opak } \\
\text { ketan }\end{array}$ & \multicolumn{2}{|c|}{$\begin{array}{l}1 \text { Mesin, } 1 \text { orang pekerja dengan penghematan waktu selama } 2 \\
\text { jam }\end{array}$} \\
\hline
\end{tabular}




\section{Kesimpulan}

Pelaksanakan Pengabdian Masyarakat Kolaborasi Ekternal yang bekerjasama dengan CSR PT. PLN (Persero) UPP - JBT 2 dan Desa Karedok Kecamatan Jatigede Sumedang, bagi masyarakat pengrajin opak ketan di Desa tersebut, dapat terlaksana sesuai dengan rencana dan harapat masyarakat pengrajin opak ketan meliputi:

a. Penyerahan genset, mesin penumbuk nasi ketan, alat cetak opak ketan, oven opak ketan dan mesin pematangan opak ketan;

b. Pelatihan pengoperasian mesin penumbuk nasi ketan, alat cetak opak ketan, oven opak ketan dan mesin pematangan opak ketan;

c. Penghematan waktu proses produksi memanfaatkan mesin produksi dalam 1 (satu) kali proses produksi selama 11,5 jam.

\section{DAFTAR PUSTAKA}

Mott, Robert L., 2009, Elemen-Elemen Mesin Dalam Perancangan Mekanis : Perancangan Elemen Mesin Terpadu, Andi Ofset, Yogyakarta;

Shigley, J.F., 1986, Perencanaan Teknik Mesin Edisi keempat Jilid 2, Erlangga, Jakarta;

Sularso, 1983, Dasar Perencanaan Dan Pemilihan Elemen Mesin, Pradya Paramita, Jakarta;

Sularso dan Suga Kiyokatsu, 2004, Mesin dan Rangkaian Listrik, Erlangga, Edisi keenam, Jakarta;

Vincent Gaspersz, 1992, Analisis Sistem terapan Berdasarkan Pendekatan Teknik industri, Tarsito, Bandung;

Widodo, I. D., 2003, Perencanaan dan Pengembangan Produk, UII Press, Yogyakata, 2003 